to this discourse in which, assuming the four-dimensional presentation, he would state explicitly, either in general terms or by precise illustration, how he would compare the intervals between any two pairs of events.

\section{E. Cunningham.}

\section{The Marketing of Whole Milk.}

The Marketing of Whole Milk. By Dr. H. E. Erdman. (The Citizen's Library: Marketing Series.) Pp. xvi +333 . (New York: The Macmillan Company; London : Macmillan and Co., Ltd., r92I.) 21s. net.

T $\mathrm{HE}$ recent disputes concerning the price of milk have again shown how difficult the problem has become under modern conditions, more especially in the large towns. The farmer is no longer able to take his milk direct to the consumer except in the case of a village or small town, and there has arisen a class of dealers or distributors who occupy the place of the middleman. Some of these distributors are large companies with the command of much capital, and their powerful organisations have led to something very like monopoly. The producers, on the other hand, have also organised themselves, and a struggle between the two parties has recently ended. In the volume under notice, this question as it appears in the United States is very completely analysed, and Prof. Erdman, who is an economist, has dealt with it more fully and critically than has previously been attempted. After discussing the peculiar position occupied by milk as a foodstuff, and the regulations which the public health authorities of all civilised countries have imposed, the author takes marketing and distribution, instances what has been done in the past and states the present position. The part played by the middleman and dealer is made clear, and the rise of collective bargaining is illustrated by the action of the Orange County farmers in their successful fight with the New York dealers in $188_{3}$, which may be regarded as the beginning of what has now become the general practice in the large American cities. The strike-or better the boycott-has been the weapon of the producers, and experience has shown that it is two-edged, owing to the difficulty which the farmer has in disposing of his milk -a perishable commodity-except by making it into cheese or butter or, at worst, by feeding it to stock, all of which courses are seldom remunerative. It is made clear that the producers must also submit to regulations governing their combined action, otherwise the results are doomed to failure.

Other matters dealt with are the difficulty of arriving at the cost of milk, owing to the position of the farm, the ability of the farmer, the proximity to market, and so on, and it is laid down that the method of arriving a a basic price can only be a starting-point in negotiations

This book, which makes a strong appeal to the genera reader, will be of interest to all concerned in the mill trade, whether as producers, distributors, or consumers and it should lead to what the author regards as thi only solution of the difficulty- " a better understandin all round."

\section{Our Bookshelf.}

Proceedings of the London Mathematical Society. Second Series. Vol. 20. Pp. liv+502. (London: F. Hodgson, 1922.) n.p.

THE present volume of the London Mathematical Society's Proceedings is the fifty-fifth issued since the foundation of the society and the twentieth in the present (large octavo) series. Like the preceding volumes issued by the society, it consists mainly of papers which embody original investigations on various mathematical subjects. Many of the papers, of which there are nearly forty, will appeal only to a limited class of reader. In mathematics, even more than in other sciences, the results of new investigations are apt to appear abstruse to the lay mind. The solution of a cubic equation, the Newtonian theory of gravitation, even the elementary applications of the calculus, fundamental and well known as they are now, were not familiar to the world, or even to the general run of university students, for many years after their discovery. By providing facilities for the publication of these specialised researches the London Mathematical Society has earned the deep obligation of the English mathematical world. Practically all the society's income is expended in producing its Proceedings, and, in view of the increased cost of printing, a large membership is essential to provide adequate funds. Inasmuch as every man is a debtor to his profession, every English mathematician should help to further the work of the society by becoming a member.

In the volume under review the articles most likely to appeal to the general reader are the excellent obituary notices of the late Lord Rayleigh and Herr Adolf Hurwitz, written by Profs. Lamb and Young respectively. There is also printed a presidential address on "Some Problems in Wireless Telegraphy" by Prof. Macdonald. Of the more technical papers it would be invidious to single out any one for special mention. The society insists on a high standard of excellence in everything it prints, and the inclusion of a paper in the Proceedings is a sufficient guarantee of quality. We notice that there is an almost entire absence of pure geometry from the present volume. Can it be that research in this subject is no longer encouraged in England?

The method of indexing each individual volume of the Proceedings leaves nothing to be desired. A subject index to the first thirty volumes of the first series was issued many years ago. We suggest that the time is approaching when the Council should consider the desirability of publishing a further subject index to the later volumes.
W. E. H. B.

No. 2765 , VOL. IIO] 